Open Access

\title{
Panax Notoginseng flower saponins (PNFS) inhibit LPS-stimulated NO overproduction and iNOS gene overexpression via the suppression of TLR4-mediated MAPK/NF-kappa B signaling pathways in RAW264.7 macrophages
}

Xiao-Xu Peng ${ }^{1+}$, Shu-Hui Zhang ${ }^{3+}$, Xiao-Ling Wang ${ }^{1}$, Ting-Jie Ye ${ }^{1}$, Hua Li ${ }^{1}$, Xiao-Feng Yan ${ }^{1}$, Li Wei ${ }^{4}$, Zhong-Ping $\mathrm{Wu}^{5}$, Jing $\mathrm{Hu}^{5}$, Chun-Pu Zou ${ }^{5}$, You-Hua Wang ${ }^{2^{*}}$ and $\mathrm{Xu}$-Dong $\mathrm{Hu}^{{ }^{*}}$

\begin{abstract}
Background: Panax Notoginseng flower saponins (PNFS) are the main active component of Panax notoginseng (Burk) F. H. Chen flower bud (PNF) and possess significant anti-inflammatory efficacy. This study aims to explore the mechanisms underlying PNFS' antiflammatory action in RAW264.7 macrophages.

Methods: A cell counting kit-8 assay was used to determine the viability of RAW264.7 macrophages. Anti-inflammation effects of PNFS in lipopolysaccharide (LPS)-stimulated RAW264.7 macrophages were measured based on the detection of nitric oxide (NO) overproduction (Griess method, DAF-FM DA fluorescence assay and $\mathrm{NO}_{2}^{-}$scavenging assay), and interleukin (IL)-6 and tumor necrosis factor (TNF)-alpha gene overexpression (real-time PCR and ELISA). Inducible nitric oxide synthase (iNOS) gene overexpression was determined by real-time PCR and western blotting. iNOS enzyme activity was also assayed. The mechanisms underlying the suppression of iNOS gene overexpression by PNFS were explored using real-time PCR and western blotting to assess mRNA and protein levels of components of the Toll-like receptor 4 mitogen-activated protein kinase (MAPK), phosphatidylinositol 3-kinase (PI3K)/Akt, and nuclear factor-kappa B (NF-kappa B) signaling pathways.

Results: PNFS (50, 100, $200 \mu \mathrm{g} / \mathrm{mL})$ significantly reduced LPS-induced overproduction of NO $(P<0.001, P<0.001$, $P<0.001)$ and IL-6 $(P=0.103, P<0.001, P<0.001)$, but did not affect TNF-alpha overproduction. PNFS $(50,100$, $200 \mathrm{\mu g} / \mathrm{mL})$ also markedly decreased LPS-activated iNOS $(P<0.001, P<0.001, P<0.001)$ and TLR4 gene overexpression $(P=0.858, P=0.046, P=0.005)$. Furthermore, treatment with PNFS $(200 \mu \mathrm{g} / \mathrm{mL})$ suppressed the phosphorylation of MAPKs including P38 $(P=0.001)$, C-Jun N-terminal kinase (JNK) $(P=0.036)$ and extracellular-signal regulated kinase (ERK) $1 / 2(P=0.021)$. PNFS $(200 \mu \mathrm{g} / \mathrm{mL})$ inhibited the activation of the NF-kappa B signaling pathway by preventing the phosphorylation of inhibitor of NF-kappa B alpha (I-kappa B alpha) $(P=0.004)$ and P65 $(P=0.023)$, but PNFS $(200 \mu \mathrm{g} / \mathrm{mL})$ could not activate the LPS-induced PI3K-Akt signaling pathway.
\end{abstract}

Conclusions: PNFS significantly down-regulated iNOS gene overexpression and thereby decreased NO overproduction via the inhibition of TLR4-mediated MAPK/NF-kappa B signaling pathways, but not the PI3K/Akt signaling pathway.

\footnotetext{
*Correspondence: doctorwyh@163.com; huxudongsh@126.com

${ }^{\dagger}$ Equal contributors

${ }^{2}$ Hypertension Laboratory, Cardiovascular Department, Long Hua Hospital affiliated to Shanghai University of Traditional Chinese Medicine, Shanghai 200032, People's Republic of China

'Department of Biology, School of Basic Medical Science, Shanghai University of Traditional Chinese Medicine, Shanghai 201203, People's Republic of

China

Full list of author information is available at the end of the article
}

C Biomed Central (c) 2015 Peng et al. This is an Open Access article distributed under the terms of the Creative Commons Attribution License (http://creativecommons.org/licenses/by/4.0), which permits unrestricted use, distribution, and reproduction in any medium, provided the original work is properly credited. The Creative Commons Public Domain Dedication waiver (http://creativecommons.org/publicdomain/zero/1.0/) applies to the data made available in this article, unless otherwise stated. 


\section{Background}

Panax notoginseng (Burk) F. H. Chen flower bud (PNF) can be used to treat hypertension closely related to inflammatory response $[1,2]$, chemotherapy stomatitis, pharyngitis and other inflammatory diseases [3-5]. The methanol extract of PNF was shown to block the NFkappa B signaling pathway and alleviate the lipopolysaccharide (LPS)-induced inflammatory response in murine macrophages [6].

Panax notoginseng flower saponins (PNFS), extracted from PNF, were reported to be the main bioactive constituent underlying PNF's therapeutic effect [7]. Additionally, the flower was shown to contain most of the total saponin amount, more than is present in the root [7]. The composition of PNFS is different from that of Panax notoginseng saponins (PNS), extracted from the Panax notoginseng (Burk) F. H. Chen (PN) root [7]. PNFS lowered blood pressure in spontaneous hypertensive rats $[8,9]$. Additionally, PNFS could relieve the inflammatory response via diminishing swelling and decreasing prostaglandin production in carrageenaninduced rat paw swelling and croton oil-induced mouse auricle inflammation, induced by proinflammatory agents $[10,11]$. Therefore, the antihypertensive effect of PNFS might be partially associated with its antiinflammatory effect.

Excessive inflammation causes the body to be overexposed to inflammatory mediators, e.g., nitric oxide (NO), tumor necrosis factor (TNF)-alpha and interleukin (IL)-6, leading to cell necrosis, tissue injury and degeneration, and consequently, aggravating inflammation. Lipopolysaccharide (LPS) is a highly proinflammatory endotoxin from the outer envelope of gram-negative bacteria. Monocytederived macrophages, when stimulated with LPS, produce excessive inflammatory mediators such as NO, TNF-alpha and IL-6, in inflammatory response [12-14].

NO significantly influences the regulation of neurotransmission and inflammatory responses $[15,16]$. In mammals, $\mathrm{NO}$ is generated by three different nitric oxide synthases (NOSs), namely, endothelial NOS (eNOS), neuronal NOS (nNOS), and inducible NOS (iNOS) [17]. iNOS, primarily identified in macrophages, is usually not expressed in normal conditions, but is expressed when induced by agents such as LPS and some cytokines [17]. In macrophages stimulated with LPS, iNOS produces large amounts of NO and exerts anti-inflammatory effects on the organism by killing undesired microbes and parasites [18]. However, when released at the wrong site or produced excessively in vivo, $\mathrm{NO}$ may aggravate inflammation via oxidative damage to healthy cells and tissues $[19,20]$. Therefore, the suppression of iNOS gene overexpression to reduce NO overproduction is an important target of anti-inflammatory drugs.
Toll-like receptor 4 (TLR4) is an essential cell surface protein on macrophages for LPS recognition [21]. The interaction between TLR4 and LPS activates two main intracellular signaling pathways: the mitogen-activated protein kinase (MAPK)/nuclear factor-kappa B (NFkappa B) signaling pathway and the phosphatidylinositol 3-kinase (PI3K)/Akt signaling pathway. Both are involved in iNOS gene expression [13, 22, 23].

This study aims to explore the suppressive effects of PNFS on proinflammatory mediator overexpression in LPS-activated RAW264.7 macrophages. Therefore, the mechanisms by which PNFS inhibits iNOS gene overexpression were studied through analysis of the levels of components of the TLR4, MAPK, PI3K/Akt, and NFkappa B signaling pathways.

\section{Methods}

\section{Reagents}

LPS (Escherichia coli O55:B5) and sulfanilic acid were bought from Sigma Chemical Co., Ltd. (St.Louis, MO, USA). Dulbecco's modified Eagle medium (DMEM) and fetal bovine serum (FBS) were purchased from Gibco BRL Co., Ltd. (Grand Island, NY, USA). Cell Counting Kit-8 (CCK-8) was purchased from Dojindo (Kumamoto, Japan) and TRIzol was purchased from Invitrogen (Carlsbad, CA, USA). RevertAid ${ }^{\mathrm{mi}}$ First Strand cDNA Synthesis Kit was purchased from Thermo Scientific (Waltham, MA, USA). SYBR ${ }^{\circ}$ Premix Ex Taq ${ }^{\text {mix }}$ (Perfect Real Time) was purchased from Takara Biotechnology (Dalian) Co., Ltd (Dalian, China). Ethanol, N-(1-naphthyl) ethylenediamine dihydrochloride, $\mathrm{H}_{3} \mathrm{PO}_{4}$, sulfanilamide, $\mathrm{NaNO}_{2}$ and hydrochloric acid were purchased from Sinopharm Chemical Reagent Co., Ltd. (Shanghai, China). 3-Amino, 4-aminomethyl-2', 7'-difluorescein, diacetate (DAF-FM DA) and cycloheximide (CHX) were purchased from Beyotime (Shanghai, China). Enzyme-linked immunosorbent assay (ELISA) kit for TNF-alpha was obtained from R\&D Systems (Minneapolis, MN, USA) and ELISA kit for IL-6 was purchased from BD PharMingen (San Diego, CA, USA). Antibodies for GAPDH (\#2118), iNOS (\#2982), P38 (\#8690), P-P38 (\#4511), ERK (\#4695), P-ERK (\#4370), JNK (\#9258), P-JNK (\#4668), I-kappa B alpha (\#4812), P-I-kappa B alpha (\#2859), P65 (\#4764), PP65 (\#3033), P-Akt (\#4056), PI3K (\#4255), anti-rabbit IgG, and HRP-linked antibody (\#7074) were purchased from Cell Signaling Technology (Boston, MA, USA).

\section{PNFS extract}

PNF was collected from Wenshan, Yunnan Province, China, and identified by Dr. Xiuming Cui, Wenshan Institute of Sanqi Research. The voucher specimens were deposited in the Pharmaceutical Laboratory, College of Pharmacy, Shanghai University of Traditional Chinese Medicine. During the preparation of total saponins, we 
took three factors into consideration: ethanol concentration, extraction time, and duration for one extraction course. The optimum extraction process determined using an orthogonal experiment design was refluxing PNF in 14 volumes of $70 \%$ ethanol, three times, for $2 \mathrm{~h}$ each time. The macroporous resin AB-8 (diameter: height $=1: 10$; weight: raw material $=1: 1.25$ ) was chosen to concentrate PNF extract, and the concentration of the raw material was $0.2 \mathrm{~g} / \mathrm{mL}$. The extract was washed until the Molisch reaction disappeared, and then eluted with three column volumes of $70 \%$ ethanol. Flow rates for absorption and elution were two column volumes per hour. Total PNF saponin extract was ready after drying and quantified to be $95 \%$ pure using a UV spectrophotometer (UV 8453, Agilent Technologies, Santa Clara, CA, USA).

\section{Cell culture}

Murine RAW264.7 macrophages were purchased from the Shanghai Cell Bank of Chinese Academy of Sciences (China). RAW264.7 macrophages were cultured in DMEM supplemented with $10 \%$ FBS, $100 \mathrm{U} / \mathrm{mL}$ penicillin and $100 \mathrm{U} / \mathrm{mL}$ streptomycin. Cells were grown at $37{ }^{\circ} \mathrm{C}$ in a humidified incubator with $5 \% \mathrm{CO}_{2}$.

\section{Cell viability}

A CCK- 8 assay was used to determine the viability of RAW264.7 macrophages. A total of $1 \times 10^{5}$ cells per well were grown in triplicate in 96-well plates. Cells were treated without or with PNFS $(0,25,50,100,200,400$, $800 \mu \mathrm{g} / \mathrm{mL}$ ) for $24 \mathrm{~h}$, and then incubated with CCK-8 $(20 \mu \mathrm{L} /$ well $)$ for $1.5 \mathrm{~h}$, after which absorbance at $450 \mathrm{~nm}$ was measured.

\section{Measurement of nitrite overproduction in cell culture supernatant}

The level of nitrite $\left(\mathrm{NO}_{2}^{-}\right)$in the cell culture supernatant, stably generated during $\mathrm{NO}$ reactions, was assessed to determine the amount of NO production. First, $1 \times 10^{5}$ Raw264.7 macrophages per well were grown in triplicate in 96-well plates. Cells were treated with LPS $(1 \mu \mathrm{g} / \mathrm{mL})$ and PNFS at different concentrations $(0,50,100$, $200 \mu \mathrm{g} / \mathrm{mL}$ ) for $24 \mathrm{~h}$, or untreated (control). Second, Griess reagent was prepared by mixing $0.1 \% \mathrm{~N}-(1-$ naphthyl) ethylenediamine dihydrochloride (dissolved in $\mathrm{ddH}_{2} \mathrm{O}$ ) and $1 \%$ sulfanilamide (dissolved in $5 \% \mathrm{H}_{3} \mathrm{PO}_{4}$ ) in equal volume. Lastly, $100 \mu \mathrm{L}$ of culture supernatant and $100 \mu \mathrm{L}$ of Griess reagent were blended with a micropipette and set aside for $10 \mathrm{~min}$ at room temperature, then the absorbance at $540 \mathrm{~nm}$ was measured. A $\mathrm{NaNO}_{2}$ standard curve was used to calculate nitrite concentration [24].

\section{Measurement of intracellular NO production}

DAF-FM DA was used to detect intracellular NO production. First, $1 \times 10^{5}$ Raw264.7 macrophages per well were grown in triplicate in 96-well plates. Cells were treated with LPS $(1 \mu \mathrm{g} / \mathrm{mL})$ and PNFS at different concentrations $(0,50,100,200 \mu \mathrm{g} / \mathrm{mL})$ for $24 \mathrm{~h}$, or untreated (control). Then, the culture supernatant was removed and cells were incubated with DAF-FM DA ( $5 \mathrm{mM}, 100 \mu \mathrm{L} /$ well) at $37{ }^{\circ} \mathrm{C}$ for $20 \mathrm{~min}$. Fluorescence values (excitation $495 \mathrm{~nm}$, emission $515 \mathrm{~nm}$ ) were measured using a Multimode Microplate Reader (Synergy ${ }^{\mathrm{Tm}} 2$, BioTek, Winooski, Vermont, USA).

\section{$\mathrm{NO}_{2}^{-}$scavenging assay}

'A $5 \mathrm{~mL}$ total reaction mixture, containing $3 \mathrm{~mL}$ of $\mathrm{NaNO}_{2}(5 \mu \mathrm{g} / \mathrm{mL})$ and $2 \mathrm{~mL}$ of PNFS $(50,100,200 \mu \mathrm{g} / \mathrm{mL}$ dissolved by $\mathrm{ddH}_{2} \mathrm{O}$ ) or $2 \mathrm{~mL}$ of $\mathrm{ddH}_{2} \mathrm{O}_{2}$ was incubated at $37{ }^{\circ} \mathrm{C}$ for $30 \mathrm{~min}$. Then, $2 \mathrm{~mL}$ of $0.4 \%$ sulfanilic acid (dissolved in $20 \%$ hydrochloric acid) was added to the reaction mixture, which was incubated for $5 \mathrm{~min}$. Lastly, $17 \mathrm{ml}$ of $\mathrm{ddH}_{2} \mathrm{O}$ and $1 \mathrm{ml}$ of $0.2 \% \mathrm{~N}$-(1-naphthyl) ethylenediamine dihydrochloride (dissolved in $\mathrm{ddH}_{2} \mathrm{O}$ ) were added, mixed and incubated for $15 \mathrm{~min}$, and absorbance at $540 \mathrm{~nm}$ was measured [25].

\section{Measurement of IL-6 and TNF-alpha overproduction}

Raw264.7 macrophages $\left(1 \times 10^{5}\right.$ per well $)$ were grown in triplicate in 96-well plates and treated with LPS $(1 \mu \mathrm{g} /$ $\mathrm{mL})$ and PNFS at different concentrations $(0,50,100$, $200 \mu \mathrm{g} / \mathrm{mL}$ ), or untreated (control), for $24 \mathrm{~h}$, to detect the inhibitory effects of PNFS on pro-inflammatory cytokines produced by LPS-activated cells. Then, culture supernatants were collected and commercial ELISA kits were used to measure IL- 6 and TNF-alpha concentrations.

\section{Measurement of iNOS enzymatic activity}

A total of $1 \times 10^{5}$ RAW264.7 macrophages per well were grown with LPS $(1 \mu \mathrm{g} / \mathrm{mL})$ in triplicate in 96-well plates for $24 \mathrm{~h}$. Then, cells were washed and treated with $1 \mu \mathrm{g} /$ $\mathrm{mL}$ cycloheximide (CHX) and PNFS at different concentrations $(0,50,100,200 \mu \mathrm{g} / \mathrm{mL})$ for the next $24 \mathrm{~h}$. Finally, the culture supernatants were harvested to detect $\mathrm{NO}_{2}^{-}$content [24].

\section{Western blotting analysis}

A total of $1 \times 10^{6}$ RAW264.7 macrophages per well were grown in 12-well plates and treated with LPS $(1 \mu \mathrm{g} / \mathrm{mL})$ and PNFS at different concentrations $(0,50,100$, $200 \mu \mathrm{g} / \mathrm{ml})$ for $24 \mathrm{~h}$, with LPS $(1 \mu \mathrm{g} / \mathrm{mL})$ and PNFS at different concentrations $(0,200 \mu \mathrm{g} / \mathrm{ml})$ for $3 \mathrm{~h}$, or untreated (control). Then, cells were harvested on ice and washed once with ice-cold PBS. Lysis buffer with phosphatase and protease inhibitors (Sangon Biotech, China) was added to lyse the cells. After incubating on ice for 
$30 \mathrm{~min}$, cell extracts were centrifuged at $14,463 \times g$ in a refrigerated centrifuge (5418R, Eppendorf, Germany) at $4{ }^{\circ} \mathrm{C}$ for $10 \mathrm{~min}$ to collect cell total proteins, the amount of which was quantified using a BCA protein assay kit (Biomiga, USA). SDS-PAGE (10 \%) was used to separate proteins, which were electro-transferred to PVDF membranes (Millipore, USA). Membranes were blocked with $5 \%$ (wt/vol) dried skimmed milk for $1 \mathrm{~h}$, and incubated with various specific primary antibodies, namely, antiGAPDH, anti-iNOS, anti-P38, anti-P-P38, anti-ERK, anti-P-ERK, anti-JNK, anti-P-JNK, anti-I-kappa B alpha, anti-P-I-kappa B alpha, anti-P65, anti-P-P65, anti-PI3K and anti-P-Akt, to probe corresponding target proteins. Bound antibodies were detected using peroxidaseconjugated secondary antibodies, and the amount of bound antibody was assessed by enhanced chemiluminescence (ECL). Relative levels of target proteins were obtained based on the optical density of electrophoresis bands with GAPDH serving as an internal control.

\section{Real-time PCR analysis}

A total of $1 \times 10^{6}$ RAW264.7 macrophages per well were grown in 12-well plates and treated with LPS $(1 \mu \mathrm{g} / \mathrm{mL})$ and PNFS at different concentrations $(0,50,100$, $200 \mu \mathrm{g} / \mathrm{mL}$ ) for $24 \mathrm{~h}$, or untreated (control). The Trizol method [26] was used to isolate total RNA from the cells in each well. Then, $1 \mu \mathrm{g}$ of total RNA was reverse transcribed into cDNA, which was amplified by real-time PCR. The 2- $\triangle C T$ method was used to analyze gene expression and beta-actin mRNA served as an internal control to quantify the levels of target mRNAs relatively. The cycling conditions were as follows: hold: $95{ }^{\circ} \mathrm{C}$ for $10 \mathrm{~s}$; cycling: $95{ }^{\circ} \mathrm{C}$ for $5 \mathrm{~s}, 60{ }^{\circ} \mathrm{C}$ for $30 \mathrm{~s}, 40$ cycles; melt: $65-95{ }^{\circ} \mathrm{C}$. The sequences of primers used for reverse transcription are listed below: iNOS, F: 5 '-AAGTCAAATCCTACCAAAGTGA-3', R: 5' -CCATAATACT GGTTGATGAACT-3'; beta-actin, F: 5'-CATCACTATCGGCAATGAGC-3', R: 5'-GACAGCACTGTGTT GGCATA-3'.

TLR4, F: 5'-GGCAGGTCTACTTTGGAGTCATTGC3', R: 5'-ACATTCGAGGCTCCAGTGAATTCGG-3'. TNF-alpha, F: 5'-GGCAGGTCTACTTTGGAGTCATT GC-3', R: 5' -ACATTCGAGGCTCCAGTGAATTCGG3'. IL-6, F: 5'-TCAGAATTGCCATTGCACA-3', R: 5' GTCGGAGGCTTAATTACACATG-3'.

\section{Statistical analysis}

Data are presented as means (SD). Multiple comparisons were performed using the one-Way ANOVA test followed by Student-Newman-Keuls (SNK) and least significant difference (LSD) tests. $P$ values $<0.05$ were considered to represent significant differences between means.

\section{Results}

The effect of PNFS on RAW264.7 macrophage viability

To evaluate the effect of PNFS on the viability of RAW264.7 macrophages, we applied various PNFS concentrations $(0-800 \mu \mathrm{g} / \mathrm{mL})$ and performed a CCK-8 assay. PNFS had an obvious cytotoxic effect at $400 \mu \mathrm{g} /$ $\mathrm{mL}(P<0.001)$ and $800 \mu \mathrm{g} / \mathrm{mL}(P<0.001)$, but had no cytotoxic effect at $200 \mu \mathrm{g} / \mathrm{mL}$ and lower concentrations on RAW264.7 macrophages (Fig. 1). So we chose the concentrations at 50,100, $200 \mu \mathrm{g} / \mathrm{mL}$ for further exploring the anti-inflammatory mechanisms of PNFS.

\section{PNFS suppresses NO overproduction in LPS-stimulated RAW264.7 macrophages}

The inhibitory effect of PNFS on NO overproduction in LPS-stimulated RAW264.7 macrophages was examined to evaluate the anti-inflammatory effect of PNFS. Extracellular NO concentrations were assessed by the Griess method [24] and intracellular NO concentrations were examined using a DAF-FM DA fluorescence assay. PNFS (50, 100, $200 \mu \mathrm{g} / \mathrm{mL})$ markedly decreased extracellular NO concentrations $(P<0.001, P<0.001, P<0.001)$ and intracellular NO concentrations $(P<0.001, P<0.001, P$ $<0.001$ ) (Fig. 2a and b). Meanwhile, PNFS (50, 100, $200 \mu \mathrm{g} / \mathrm{mL}$ ) did not have a $\mathrm{NO}_{2}^{-}$scavenging effect (Fig. 2c), which would affect the authenticity of NO detection results obtained using the Griess method. In summary, our experiments showed that PNFS suppressed LPS-stimulated NO overproduction.

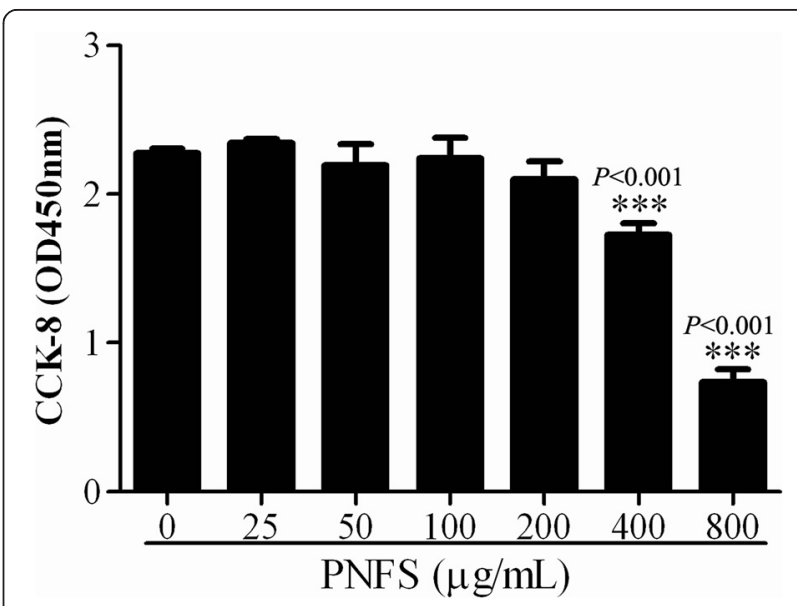

Fig. 1 Effect of PNFS on RAW264.7 macrophage viability. Data were expressed as the mean (SD) of 3 independent experiments. One-Way ANOVA test was used to analyzed the data and the result was $F=87.693 ; P<0.001$. Then, data were counted by SNK and LSD multiple comparisons to determine the statistical difference between two groups. The $P$ values represented the statistical differences between each group and negative control group (without PNFS treated). ${ }^{* * *}$ means $P<0.001$ 

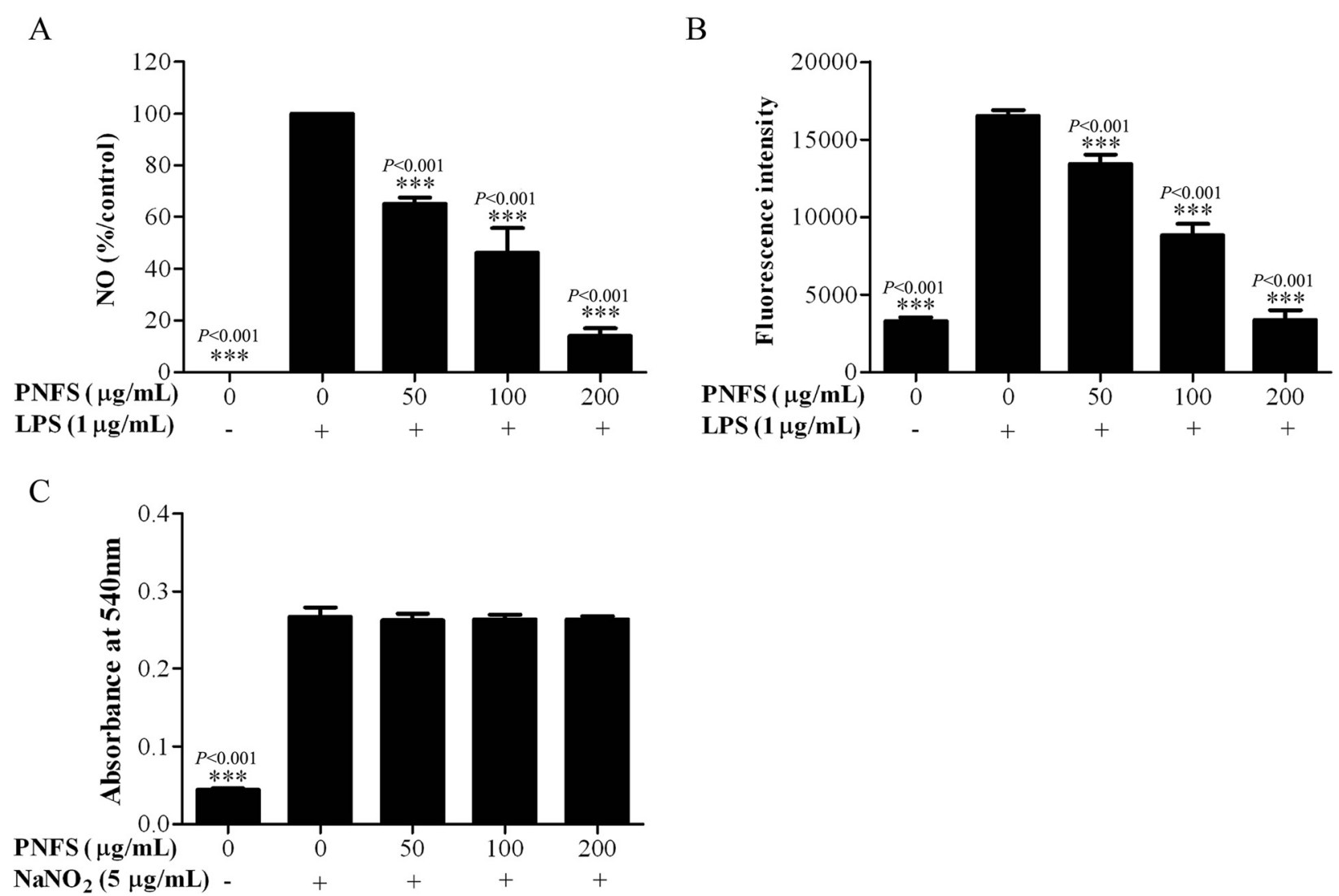

Fig. 2 PNFS suppressed NO overproduction in LPS-stimulated RAW264.7 macrophages. a PNFS decreased LPS-stimulated NO overproduction in culture supernatants. b PNFS reduced LPS-stimulated intracellular NO level. c PNFS had no scavenging effect on $\mathrm{NO}_{2}^{-}$in vitro. Data in Fig. 2a, b and $\mathrm{c}$ were all expressed as the mean (SD) of 3 independent experiments. One-Way ANOVA test was used to analyzed the data and the results were $F=227.437 ; P<0.001, F=345.932 ; P<0.001$ and $F=599.919 ; P<0.001$, respectively. Then, data in Fig. $2 \mathbf{a} \mathbf{a} \mathbf{b}$ and $\mathbf{c}$ were all counted by SNK and LSD multiple comparisons to determine the statistical difference between two groups. The $P$ values represented the statistical differences between each group and the corresponding positive control (without PNFS and with LPS or $\mathrm{NaNO}_{2}$ treated). ${ }^{* * *}$ means $P<0.001$

PNFS suppresses overexpression of IL-6, but exerts no influence on TNF-alpha in LPS-stimulated RAW264.7 macrophages

To further explore the potential anti-inflammatory role of PNFS, we observed its effects on the overproduction of IL-6 and TNF-alpha and the overexpression of IL-6 and TNF-alpha mRNA in LPS-stimulated RAW264.7 macrophages by ELISA and real-time PCR, respectively. PNFS (50, 100, $200 \mu \mathrm{g} / \mathrm{mL})$ significantly inhibited IL-6 overproduction $(P=0.103, P<0.001, P<0.001)$ and IL-6 mRNA overexpression $(P=0.006, P<0.001, P<0.001)$ (Fig. 3a and b). However, PNFS (50, 100, $200 \mu \mathrm{g} / \mathrm{mL}$ ) exerted no influence on TNF-alpha gene overexpression (Fig. 3c and d).

PNFS significantly inhibits iNOS gene overexpression, but does not affect iNOS enzymatic activity in LPS-stimulated RAW264.7 macrophages

We next assessed whether PNFS inhibited NO overproduction by suppressing iNOS gene overexpression using western blotting and real-time PCR to measure total proteins and total RNA, respectively. iNOS protein and mRNA levels were significantly increased after stimulated by LPS, while PNFS (50, 100, $200 \mu \mathrm{g} / \mathrm{mL})$ apparently inhibited iNOS protein overproduction $(P<0.001$, $P<0.001, P<0.001)$ and iNOS mRNA overexpression $(P<0.001, P<0.001, P<0.001)$ (Fig. 4a and $b)$. This suggested that PNFS could decrease NO overproduction via inhibiting iNOS gene overexpression.

We then clarified whether PNFS-mediated suppression of NO overproduction was also caused by lowering iNOS catalytic activity. LPS $(1 \mu \mathrm{g} / \mathrm{mL})$ was used to activate RAW264.7 macrophages for $24 \mathrm{~h}$ first, then cells were washed and treated with CHX $(1 \mu \mathrm{g} / \mathrm{ml})$ and PNFS $(0,50,100,200 \mu \mathrm{g} / \mathrm{mL})$ for the next $24 \mathrm{~h}$. iNOS proteins had already been induced in 24 h-LPS-stimulated cells, but their further production was blocked by adding CHX, which is a translation inhibitor. Therefore, NO output only depended on the iNOS catalytic activity. PNFS $(50,100,200 \mu \mathrm{g} / \mathrm{mL})$ did not change the nitrite 


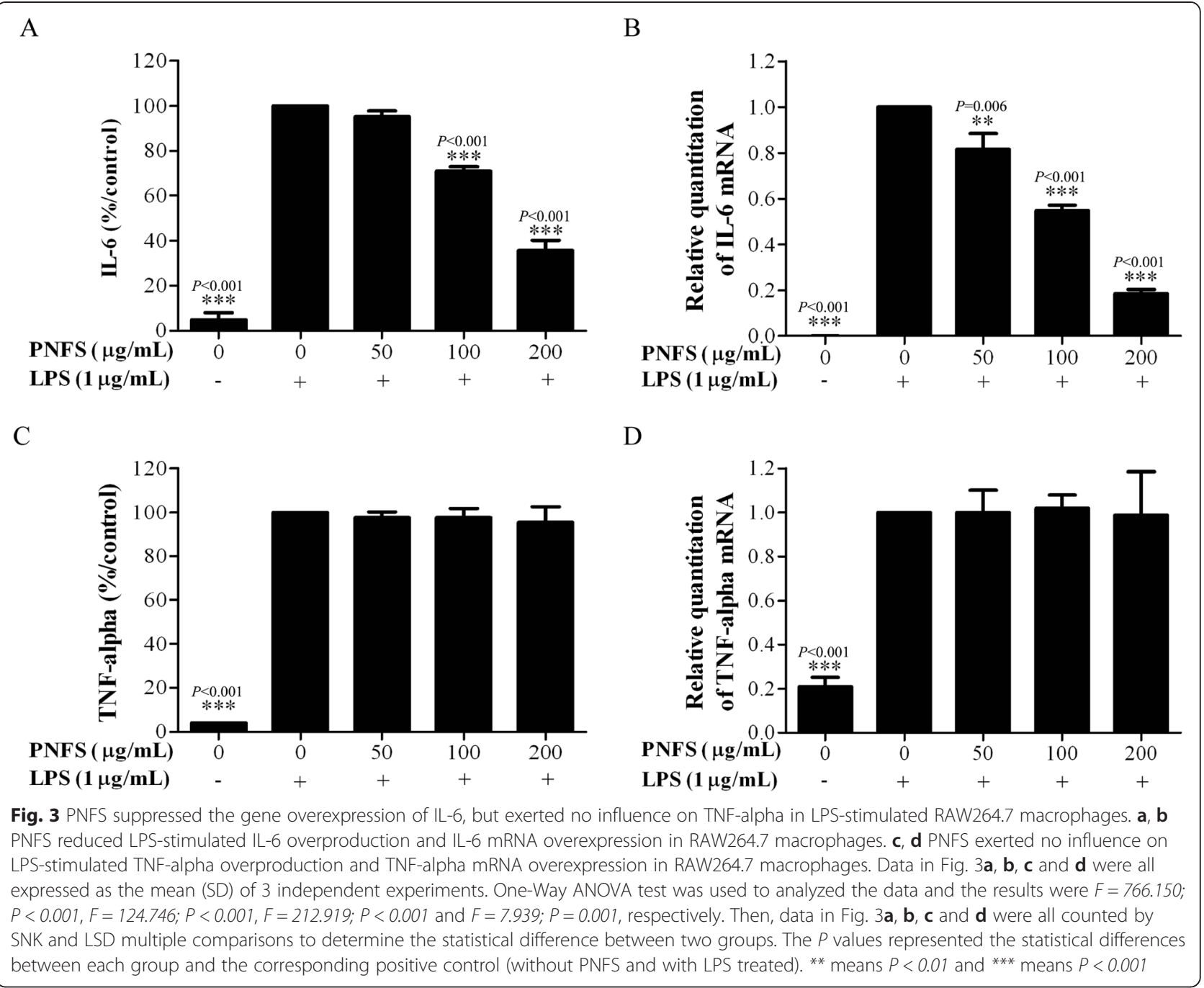

levels in cells (Fig. 4c). This suggested that PNFS did not affect the iNOS enzymatic activity in LPS-stimulated RAW264.7 macrophages.

\section{PNFS significantly inhibits the overexpression of} LPS-stimulated TLR4 mRNA in RAW264.7 macrophages iNOS gene expression is mainly induced via activation of the TLR4 signaling pathway. Total RNA was separated for real-time PCR to detect the inhibitory effects of PNFS $(0,50,100,200 \mu \mathrm{g} / \mathrm{mL})$ on LPS-induced TLR4 overexpression in macrophages. PNFS $(100,200 \mu \mathrm{g} / \mathrm{mL})$ significantly inhibited LPS-induced TLR4 mRNA overexpression $(P=0.046, P=0.005)$ (Fig. 5).

PNFS markedly suppresses activation of LPS-stimulated MAPK signaling pathway in RAW264.7 macrophages Based on the results described above, PNFS $(200 \mu \mathrm{g} / \mathrm{mL})$ had no cytotoxic effect on RAW264.7 macrophages and showed the best anti-inflammatory efficacy. RAW264.7 macrophages were treated with LPS $(1 \mu \mathrm{g} / \mathrm{ml})$ and PNFS
$(0,200 \mu \mathrm{g} / \mathrm{mL})$ for $3 \mathrm{~h}$. Then, western blotting was used to detect the levels of phospho-P38 (P-P38), phosphoERK1/2 (P-ERK1/2) and phospho-JNK (P-JNK), along with the corresponding total P38, ERK1/2 and JNK. LPS obviously increased MAPKs activation by increasing the phosphorylation of P38, ERK1/2 and JNK in LPSstimulated RAW264.7 macrophages. The overproduction of P-P38, P-ERK1/2 and P-JNK was markedly inhibited by PNFS $(200 \mu \mathrm{g} / \mathrm{mL})$ and the average inhibition rates were $45 \%, 56 \%$ and $23 \%(P=0.001, P=0.021, P=0.036)$, respectively (Fig. 6a, b and c). By contrast, PNFS (200 $\mu \mathrm{g} /$ $\mathrm{mL}$ ) did not significantly affect the production of total P38, ERK1/2 and JNK. These results demonstrated that PNFS was able to reduce iNOS gene overexpression by inhibiting the activation of MAPK signaling pathway.

PNFS does not activate the LPS-stimulated PI3K/Akt signaling pathway in RAW264.7 macrophages

iNOS gene expression can be suppressed via activating the PI3K/Akt signaling pathway [27]. In this study, the 


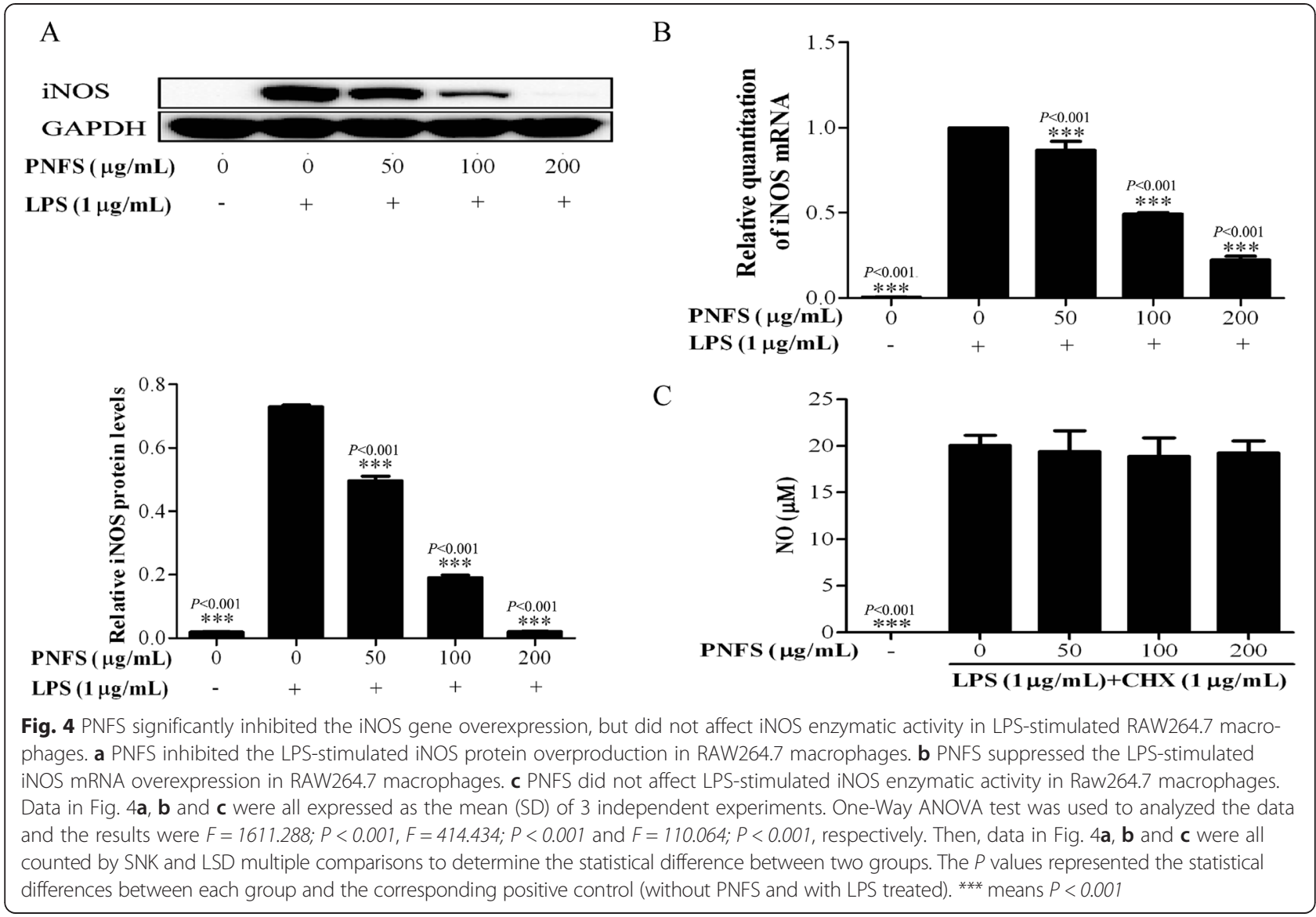

effects of PNFS on the LPS-stimulated PI3K/Akt signaling pathway in RAW264.7 macrophages were evaluated. After cells were incubated with LPS $(1 \mu \mathrm{g} / \mathrm{mL})$ and PNFS $(0,200 \mu \mathrm{g} / \mathrm{mL})$ for $3 \mathrm{~h}$, we used western blotting

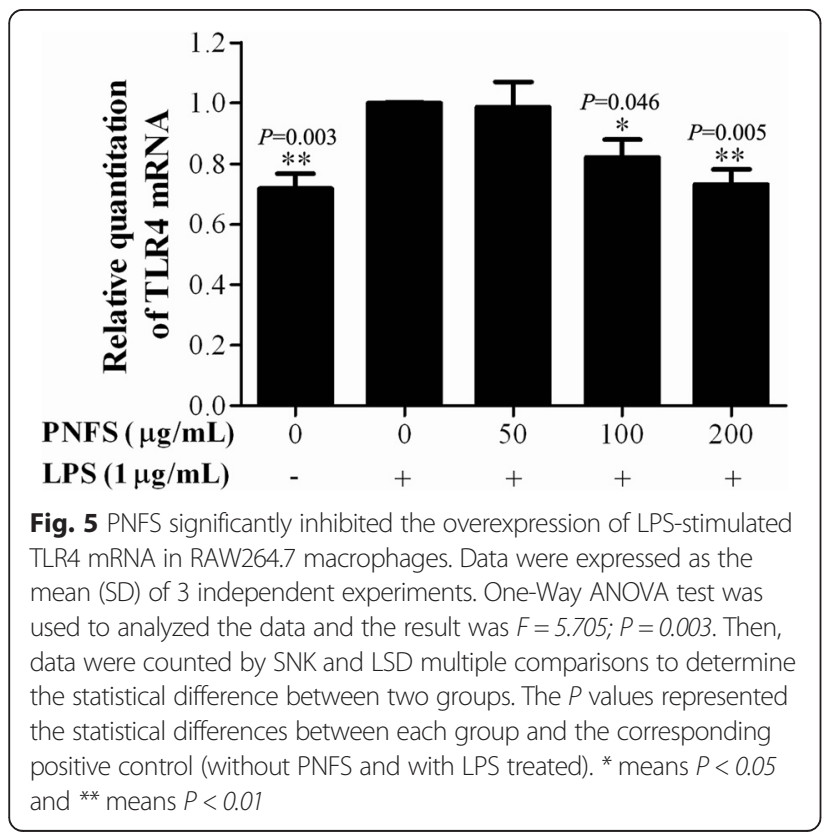

to measure the levels of PI3K and phospho-Akt (P-Akt) (Thr308). PNFS $(200 \mu \mathrm{g} / \mathrm{mL})$ did not affect levels of PI3K or P-Akt (Thr308) (Fig. 7a and b), suggesting that the PI3K/Akt signaling pathway might not be involved in the mechanism by which PNFS suppresses iNOS gene overexpression.

\section{PNFS significantly inhibits activation of the LPS-stimulated NF-kappa B signaling pathway in RAW264.7 macrophages}

To further explain the mechanisms underlying the inhibition of iNOS gene overexpression by PNFS, we studied the effects of PNFS on activation of the NFkappa B signaling pathway. After cells were treated with PNFS $(0,200 \mu \mathrm{g} / \mathrm{mL})$ and LPS $(1 \mu \mathrm{g} / \mathrm{mL})$ for $3 \mathrm{~h}$, we used western blotting to examine the phosphorylation of I-kappa B alpha and P65 and the production of corresponding total I-kappa $\mathrm{B}$ alpha and P65. The production of P-I-kappa B alpha and P-P65 were significantly enhanced after cells were challenged with LPS for $3 \mathrm{~h}(P=0.019, P=0.007)$. Treatment with PNFS $(200 \mu \mathrm{g} / \mathrm{mL})$ apparently inhibited the overproduction of P-I-kappa B alpha and P-P65 and the average inhibition rates were $38 \%$ and $30 \%(P=0.004, P=0.023)$, respectively (Fig. 8a and b). However, PNFS $(200 \mu \mathrm{g} / \mathrm{mL})$ 


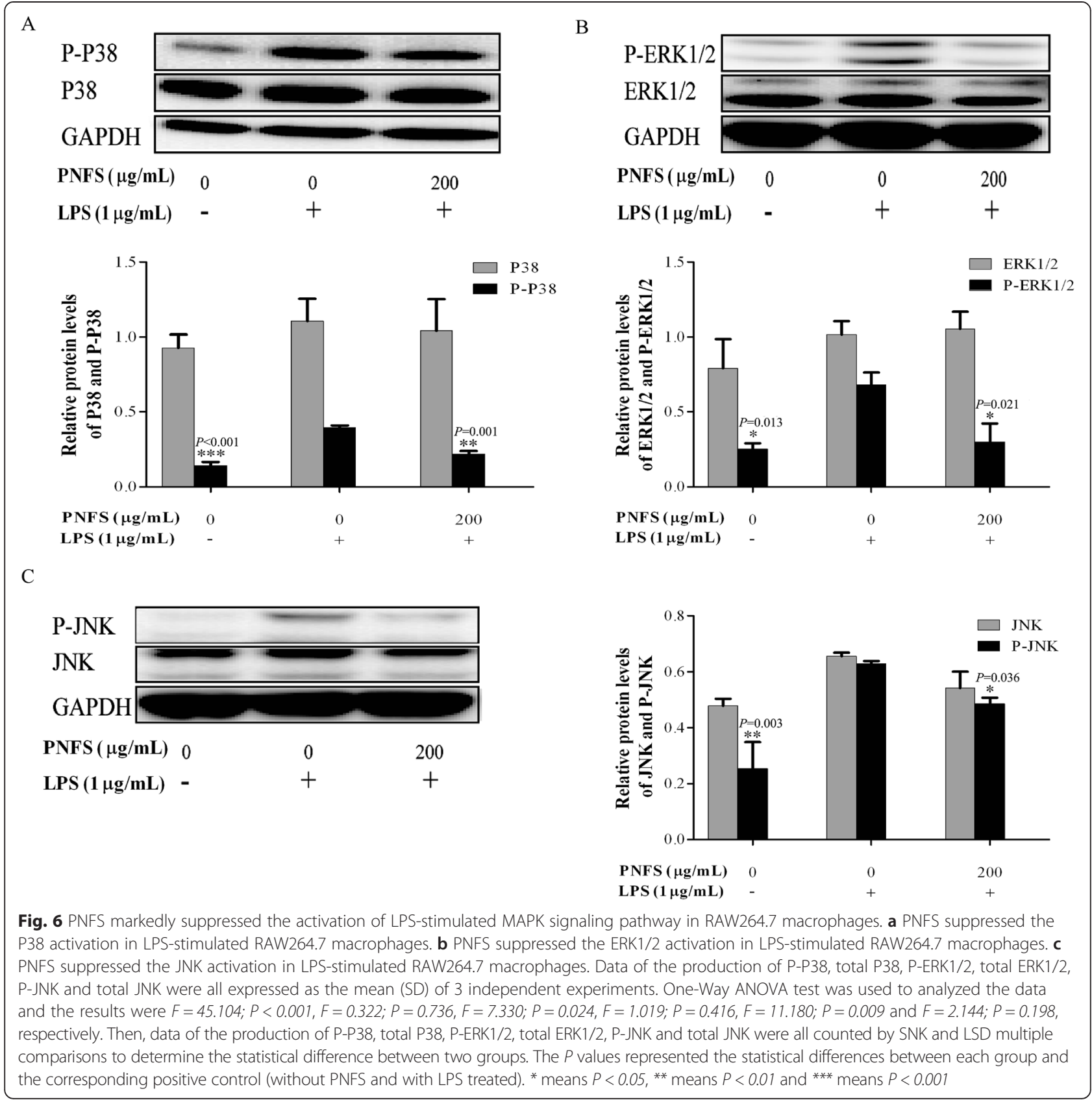

had no obvious effect on the production of total I-kappa B alpha and P65. These results suggested that PNFS could reduce iNOS gene overexpression by inhibiting NF-kappa B activation.

\section{Discussion}

Our study demonstrates, for the first time, the suppressive effects of PNFS on LPS-stimulated NO overproduction and iNOS gene overexpression in RAW264.7 macrophages. These results also partially show the mechanisms underlying the anti-inflammatory effects of
PNF, and provide a theoretical basis for the clinical treatment of inflammatory diseases with PNF.

When macrophages are stimulated with LPS, they become activated and then release various proinflammatory factors and cytokines such as IL-6, TNF-alpha and NO, whose excessive production results in extensive tissue damage and pathological changes. PNFS could significantly reduce NO and IL-6 overproduction, but did not exert any influence on TNF-alpha gene expression. As the inhibitory effect of PNFS on NO was more apparent than on IL-6, we focused on $\mathrm{NO}$ in this study. 
A
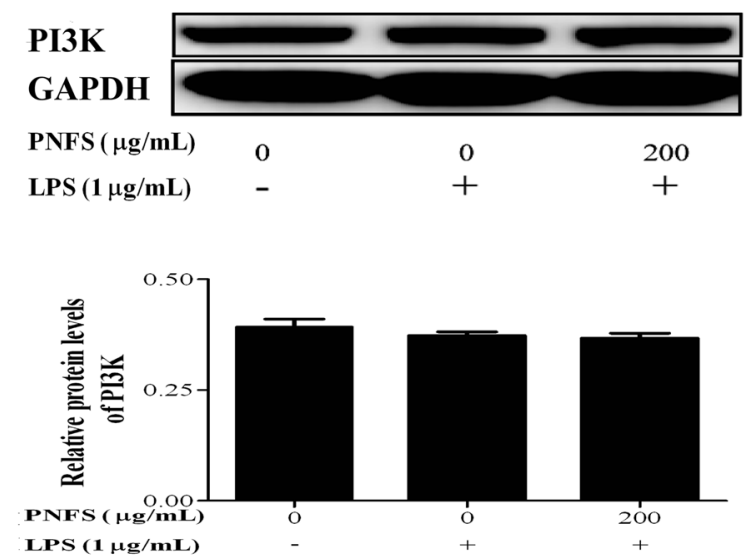

B

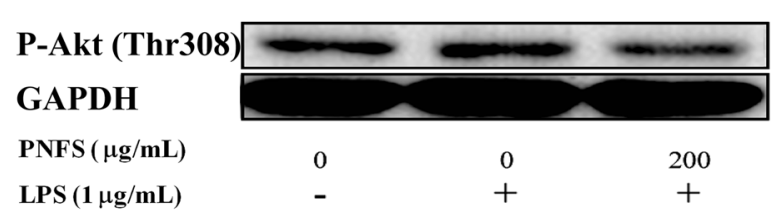

Fig. 7 PNFS did not activate LPS-stimulated PI3K/Akt signaling pathway in RAW264.7 macrophages. a PNFS had no effect on PI3K production in LPS-stimulated RAW264.7 macrophages. b PNFS had no effect on P-Akt (Thr308) production in LPS-stimulated RAW264.7 macrophages. Data in Fig. $7 \mathbf{a}$ and $\mathbf{b}$ were both expressed as the mean (SD) of 3 independent experiments. One-Way ANOVA test was used to analyzed the data and the results were $F=0.999 ; P=0.422$ and $F=0.157 ; P=0.858$, respectively. Then, data in Fig. $7 \mathbf{a}$ and $\mathbf{b}$ were both counted by SNK and LSD multiple comparisons to determine the statistical difference between two groups. The $P$ values represented the statistical differences between each group and the corresponding positive control (without PNFS and with LPS treated)

$\mathrm{NO}$ is produced via decomposition of L-arginine in a reaction catalyzed by NOSs. eNOS and nNOS are constitutively expressed, while iNOS is mainly synthesized by activated macrophages [28]. When stimulated with LPS, iNOS gene expression is increased and macrophages release excessive NO. PNFS could evidently reduce LPS-stimulated NO overproduction via potent inhibition of iNOS gene overexpression, instead of suppressing iNOS enzymatic activity.
TLR4 triggers activation of MAPK/NF-kappa B signaling pathways to induce iNOS gene overexpression [29], and the TLR4-mediated signaling pathway also rapidly activates the PI3K/Akt signaling pathway to negatively regulate iNOS gene expression [23, 30]. PNFS had an obvious suppressive effect on LPS-activated TLR4 mRNA overexpression, suggesting that PNFS could inhibit the overproduction of $\mathrm{NO}$ and the overexpression of iNOS by blocking the TLR4 signaling pathway.
A

P-IkappaBalpha
IkappaBalpha
GAPDH
PNFS $(\mu \mathbf{g} / \mathbf{m L})$
LPS $(1 \mu \mathbf{g} / \mathbf{m L})$
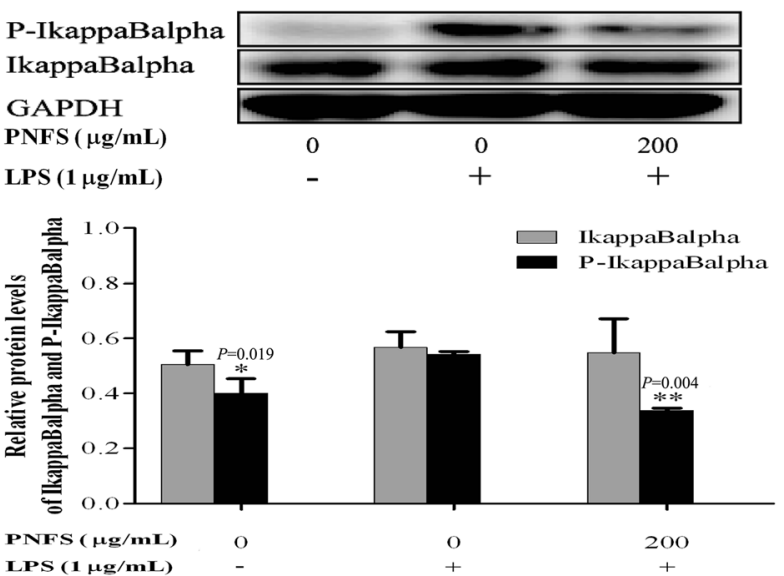

$\mathrm{B}$

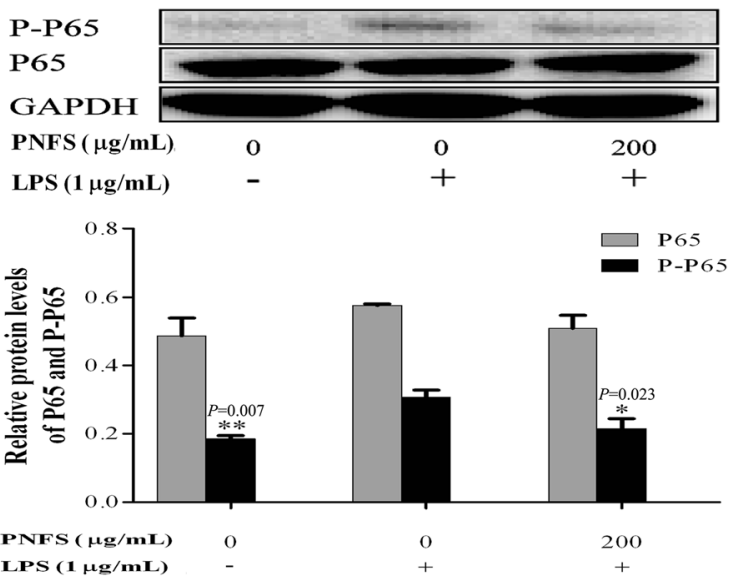

Fig. 8 PNFS significantly inhibited the activation of LPS-stimulated NF-kappaB signaling pathway in RAW264.7 macrophages. a PNFS inhibited the IkappaBalpha activation in LPS-stimulated RAW264.7 macrophages. b PNFS inhibited the P65 activation in LPS-stimulated RAW264.7 macrophages. Data of the production of P-IkappaBalpha, total IkappaBalpha, P-P65 and total P65 were all expressed as the mean (SD) of 3 independent experiments. One-Way ANOVA test was used to analyzed the data and the results were $F=11.172 ; P=0.009, F=0.146 ; P=0.867, F=8.793 ; P=0.016$ and $F=0.062$; $P=0.941$, respectively. Then, data of the production of P-IkappaBalpha, total IkappaBalpha, P-P65 and total P65 were all counted by SNK and LSD multiple comparisons to determine the statistical difference between two groups. The $P$ values represented the statistical differences between each group and the corresponding positive control (without PNFS and with LPS treated). ${ }^{*}$ means $P<0.05$ and ${ }^{* *}$ means $P<0.01$ 
MAPKs transduce signals from the cell surface to the nucleus after being activated by various extracellular stimuli [31]. There are three parallel MAPK signaling pathways in mammalian cells, the P38 signaling pathway, the extracellular signal-regulated kinase (ERK) signaling pathway and the c-Jun N-terminal kinase (JNK) signaling pathway [32]. NF-kappa B, a common transcription factor, regulates various genes encoding inflammatory mediators and acts an important downstream target of MAPK signaling pathways in inflammatory and immune responses [33, 34]. NF-kappa B-activating stimuli, such as LPS and proinflammatory factors, induce I-kappa $\mathrm{B}$ phosphorylation, leading to their rapid degradation through the ubiquitin-proteasome pathway. As a result, NF-kappa B is translocated to the nucleus, and phosphorylated P65 (P-P65), which is a subunit of NF-kappa B, triggers iNOS gene expression [35]. PNFS significantly suppressed the I-kappa B alpha phosphorylation and degradation induced by LPS, thereby inhibiting NF-kappa B activation and reducing P65 phosphorylation. Additionally, PNFS attenuated LPS-induced phosphorylation of all three MAPKs studied. These findings suggest that PNFS inactivated P38, ERK1/2 and JNK, and then suppressed the NF-kappa B signaling pathway to prohibit iNOS gene overexpression.

PI3K catalyzes the generation of phosphatidylinositol 3, 4, 5-triphosphate (PIP3), and then PIP3 induces phosphorylation of Akt [36]. The generation of phospho-Akt (P-Akt) indicates the activation of the PI3K/Akt signaling pathway. PI3K is a negative regulator of iNOS gene expression [27]. The suppression of PI3K gene expression augments LPS-stimulated iNOS production in macrophages [23]. PNFS did not affect LPS-activated PI3K generation or P-Akt (Thr308) levels, indicating that PNFS did not suppress iNOS gene overexpression via activation of the PI3K/Akt signaling pathway.

\section{Conclusions}

PNFS significantly down-regulated iNOS gene overexpression, and thereby decreased $\mathrm{NO}$ overproduction via the inhibition of TLR4-mediated MAPK/NF-kappa B signaling pathways, but not the PI3K/Akt signaling pathway.

\footnotetext{
Abbreviations

CCK-8: Cell Counting Kit-8; CHX: Cycloheximide; DAF-FM DA: 3-Amino, 4-aminomethyl-2',7'-difluorescein, diacetate; DMEM: Dulbecco's modified Eagle medium; ECL: Chemiluminescence; ELISA: Enzyme-linked immunosorbent assay; eNOS: Endothelial nitric oxide synthase; ERK1/ 2: Extracellular-signal regulated kinase 1/2; FBS: Fetal bovine serum; I-kappa B: Inhibitor of NF-kappa B; IL-6: Interleukin-6; iNOS: Inducible nitric oxide synthase; JNK: c-Jun N-terminal kinase; LSD: Least significant difference; LPS: Lipopolysaccharide; MAPKs: Mitogen-activated protein kinases; NF-kappa B: Nuclear factor-kappa B; nNOS: neuronal nitric oxide synthase; NO: Nitric oxide; $\mathrm{NO}_{2}^{-}$: Nitrite; NOSs: Nitric oxide synthases; PI3K: Phosphatidylinositol 3-kinase; PIP3: Phosphatidylinositol 3, 4, 5-triphosphate; PN: Panax notoginseng (Burk) F. H. Chen; PNF: Panax notoginseng (Burk) F. H. Chen
}

flower bud; PNFS: Panax Notoginseng flower saponins; PNS: Panax notoginseng saponins; Real-time RT-PCR: Real-time quantitative reverse transcription-polymerase chain reaction; SNK: Student-Newman-Keuls; TLR4: Toll-like receptor 4; TNF-alpha: Tumor necrosis factor-alpha.

\section{Competing interests}

The authors declare that they have no competing interests.

\section{Authors' contributions}

$X D H, Y H W$ and $X X P$ conceived and designed the study. XXP, TJY, XFY, HL, LW, ZPW, JH and CPZ performed the experiments. SHZ and XLW analyzed the data; XDH and XXP wrote and revised the manuscript. All authors approved the final manuscript.

\section{Acknowledgements}

This work was supported by the First-class Academic Discipline Project of Shanghai Municipal Education Commission (1006), the "Xinglin Scholars" alents and Professionals Project of Shanghai University of Traditional Chinese Medicine (A1-20141007), the Teachers' Academic Community Project of Shanghai University of Traditional Chinese Medicine (P304030105), the Shanghai Natural Science Foundation (No. 12ZR1432200) and the National Natural Science Foundation of China (NO.81328025, 81173200, 30600827).

\section{Author details}

'Department of Biology, School of Basic Medical Science, Shanghai University of Traditional Chinese Medicine, Shanghai 201203, People's Republic of China. ${ }^{2}$ Hypertension Laboratory, Cardiovascular Department, Long Hua Hospital affiliated to Shanghai University of Traditional Chinese Medicine, Shanghai 200032, People's Republic of China. ${ }^{3}$ Yueyang Hospital, Shanghai University of Traditional Chinese Medicine, Shanghai 200437, People's Republic of China. ${ }^{4}$ School of Pharmacy, Shanghai University of Traditional Chinese Medicine, Shanghai 201203, People's Republic of China. ${ }^{5}$ School of Basic Medical Science, Shanghai University of Traditional Chinese Medicine, Shanghai 201203, People's Republic of China.

Received: 12 November 2014 Accepted: 25 June 2015

Published online: 01 July 2015

\section{References}

1. Cao M, Zhou D, Wang YH, Zhang YL, Zhou L, Liang YQ, et al. Flos Notoginseng's antihypertensive effect and its influence on plasma t-PA, PAI and vWF. Shanghai Zhong Yi Yao Za Zhi. 2012;46:47-8.

2. Savoia C, Schiffrin EL. Inflammation in hypertension. Curr Opin Nephrol Hypertens. 2006;15:152-8.

3. Jiang JF, Chen LJ, Tao HR, Lao RC, Xu L, Li CY, et al. Efficacy of notoginseng flower ice prevention of chemotherapy stomatitis. Guangxi Yi Ke Da Xue Xue Bao. 2006;23:551-2.

4. Huang ZY, Huang L, Fang ZF, Li QH, Wei D. Throat clearing and moistering clinical trial of "buccal tablet of Panax notoginseng flower". Guangxi Yi Xue. 2005;27:1765-7.

5. Zhang BH, Pan WJ, Zheng Q, Wang T, Wei JX, Shang JJ, et al. The antiinflammatory effects of Panax notoginseng flower saponin $\mathrm{f}$. Zhong Yao Yao Li Yu Lin Chuang. 1985;0:152-3.

6. Jung HW, Seo UK, Kim JH, Leem KH, Park YK. Flower extract of Panax notoginseng attenuates lipopolysaccharide-induced inflammatory response via blocking of NF-KB signaling pathway in murine macrophages. J Ethnopharmacol. 2009;122:313-9.

7. Gao X, Dan M, Zhao A, Xie G, Jia W. Simultaneous determination of saponins in flower buds of Panax notoginseng using high performance liquid chromatography. Biomed Chromatogr. 2008;22:244-9.

8. Wang YH, Zhou D, Cao M, Yuan SY, Yang JM, Wei L, et al. Influence of Panax Notoginseng Flower Saponins on Blood Pressure and Heart Rate in Spontaneous Hypertension Rats. Zhong Xi Yi Jie He Xin Nao Xue Guan Bing Za Zhi. 2007:5:965-7.

9. Cao M, Wang YH, Wang FB, Zhou D, Zhou L, Liang YQ, et al. Effect Study on Blood Pressure by Panax Notoginseng Flower Saponins. Guang Ming Zhong Yi. 2012;27:1314-5

10. Yuan HN, Liu MK, Zhao YL, Wang CD, Wei JX. Anti-inflammatory effect of Panax Notoginseng Flower Saponins. Te Chan Yan Jiu. 1987;2:3-8. 
11. Liu J, Geng XZ, Liu YP, He XZ, Wang CD. Effect Study on anti-inflammation by Panax Notoginseng Flower Saponins. Zhong Yao Tong Bao. 1985;10:41-3.

12. Ivashkiv LB. Inflammatory signaling in macrophages: transitions from acute to tolerant and alternative activation states. Eur J Immunol. 2011;41:2477-81.

13. Ci X, Ren R, Xu K, Li H, Yu Q, Song Y, et al. Schisantherin A exhibits anti-inflammatory properties by down-regulating NF-kappaB and MAPK signaling pathways in lipopolysaccharide-treated RAW 264.7 cells. Inflammation. 2010:33:126-36.

14. Yona S, Jung S. Monocytes: subsets, origins, fates and functions. Curr Opin Hematol. 2010;17:53-9.

15. Garthwaite J. Neural nitric oxide signalling. Trends Neurosci. 1995;18:51-2.

16. Nathan C, Xie QW. Nitric oxide synthases: roles, tolls, and controls. Cell. 1994;78:915-8

17. Förstermann U, Sessa WC. Nitric oxide synthases: regulation and function. Eur Heart J. 2012;33:829-37.

18. Nathan CF, Hibbs JJ. Role of nitric oxide synthesis in macrophage antimicrobial activity. Curr Opin Immunol. 1991;3:65-70.

19. Fehsel K, Jalowy A, Qi S, Burkart V, Hartmann B, Kolb H. Islet cell DNA is a target of inflammatory attack by nitric oxide. Diabetes. 1993:42:496-500.

20. Lange $M$, Enkhbaatar $P$, Nakano $Y$, Traber DL. Role of nitric oxide in shock: the large animal perspective. Front Biosci. 2009;14:1979-89.

21. Takeda K, Akira S. Toll-like receptors in innate immunity. Int Immunol. 2005;17:1-14.

22. Ha YM, Ham SA, Kim YM, Lee YS, Kim HJ, Seo HG, et al. $\beta_{1}$-adrenergic receptor-mediated $\mathrm{HO}-1$ induction, via PI3K and p38 MAPK, by isoproterenol in RAW 264.7 cells leads to inhibition of HMGB1 release in LPS-activated RAW 264.7 cells and increases in survival rate of CLP-induced septic mice. Biochem Pharmacol. 2011;82:769-77.

23. Hazeki K, Kinoshita S, Matsumura T, Nigorikawa K, Kubo H, Hazeki O. Opposite effects of wortmannin and 2-(4-morpholinyl)-8-phenyl-1 (4H)-benzopyran-4-one hydrochloride on toll-like receptor-mediated nitric oxide production: negative regulation of nuclear factor-\{kappa\}B by phosphoinositide 3-kinase. Mol Pharmacol. 2006;69:1717-24.

24. Hu XD, Yang $Y$, Zhong $X G$, Zhang $X H$, Zhang $Y N$, Zheng ZP, et al. Anti-inflammatory effects of Z23 on LPS-induced inflammatory responses in RAW264.7 macrophages. J Ethnopharmacol. 2008;120:447-51.

25. Sundararajan R, Haja NA, Venkatesan K, Mukherjee K, Saha BP, Bandyopadhyay A, et al. Cytisus scoparius link-a natural antioxidant. BMC Complement Altern Med. 2006;6:1-7.

26. Chomczynski P, Mackey K. Short technical reports. Modification of the TRI reagent procedure for isolation of RNA from Polysaccharide- and proteoglycan-rich sources. Biotechniques. 1995;19:942-5.

27. Jeong JH, Ryu DS, Suk DH, Lee DS. Anti-inflammatory effects of ethanol extract from Orostachys japonicus on modulation of signal pathways in LPS-stimulated RAW 264.7 cells. BMB Rep. 2011;44:399-404.

28. Bian K, Murad F. Nitric oxide signaling in vascular biology. J Am Soc Hypertens. 2007;1:17-29.

29. Kang GJ, Han SC, Yoon WJ, Koh YS, Hyun JW, Kang HK, et al. Sargaquinoic acid isolated from Sargassum siliquastrum inhibits lipopolysaccharideinduced nitric oxide production in macrophages via modulation of nuclear factor-kB and c-Jun N-terminal kinase pathways. Immunopharmacol Immunotoxicol. 2013:35:80-7.

30. Laird MH, Rhee SH, Perkins DJ, Medvedev AE, Piao W, Fenton MJ, et al. TLR4/MyD88/PI3K interactions regulate TLR4 signaling. J Leukoc Biol. 2009;85:966-77.

31. Li B, Lee DS, Choi HG, Kim KS, Kang DG, Lee HS, et al. Sauchinone suppresses pro-inflammatory mediators by inducing heme oxygenase-1 in RAW264.7 macrophages. Biol Pharm Bull. 2011;34:1566-71.

32. Son Y, Cheong YK, Kim NH, Chung HT, Kang DG, Pae HO. MitogenActivated Protein Kinases and Reactive Oxygen Species: How Can ROS Activate MAPK Pathways? J Signal Transduct. 2011. doi:10.1155/2011/ 792639

33. Dai JN, Zong Y, Zhong LM, Li YM, Zhang W, Bian LG, et al. Gastrodin inhibits expression of inducible NO synthase, cyclooxygenase-2 and proinflammatory cytokines in cultured LPS-stimulated microglia via MAPK pathways. PLoS One. 2011;6:e21891.

34. Baeuerle PA, Baltimore D. NF-kappa B: ten years after. Cell. 1996:87:13-20.
35. Cho W, Nam JW, Kang HJ, Windono T, Seo EK, Lee KT. Zedoarondiol isolated from the rhizoma of Curcuma heyneana is involved in the inhibition of iNOS, COX-2 and pro-inflammatory cytokines via the downregulation of NF-kappaB pathway in LPS-stimulated murine macrophages. Int Immunopharmacol. 2009;9:1049-57.

36. Bhaskar PT, Hay N. The two TORCs and Akt. Dev Cell. 2007:12:487-502.

\section{Submit your next manuscript to BioMed Central and take full advantage of:}

- Convenient online submission

- Thorough peer review

- No space constraints or color figure charges

- Immediate publication on acceptance

- Inclusion in PubMed, CAS, Scopus and Google Scholar

- Research which is freely available for redistribution 